Article

\title{
Zeolite Catalysts for Phenol Benzoylation with Benzoic Acid: Exploring the Synthesis of Hydroxybenzophenones
}

\author{
Gherardo Gliozzi, Sauro Passeri, Francesca Bortolani, Mattia Ardizzi, \\ Patrizia Mangifesta and Fabrizio Cavani *
}

Dipartimento di Chimica Industriale “Toso Montanari”, Viale Risorgimento 4, Università di Bologna, 40136 Bologna, Italy; E-Mails: gherardo_gliozzi@cargill.com (G.G.); sauro.passeri@camlinfs.com (S.P.); francesca.bortolani@googlemail.com (F.B.); mattia_ardizzi@yahoo.it (M.A.); patrizia.mangifesta@gruppohera.it (P.M.)

* Author to whom correspondence should be addressed; E-Mail: fabrizio.cavani@unibo.it; Tel.: +39-051-209-3680.

Academic Editor: Andreas Martin

Received: 14 November 2015 / Accepted: 9 December 2015 / Published: 16 December 2015

\begin{abstract}
In this paper, we report on the reaction of phenol benzoylation with benzoic acid, which was carried out in the absence of solvent. The aim of this reaction is the synthesis of hydroxybenzophenones, which are important intermediates for the chemical industry. H-beta zeolites offered superior performance compared to H-Y, with a remarkably high conversion of phenol and high yields to the desired compounds, when using a stoichiometric amount of benzoic acid. It was found that the reaction mechanism did not include the intramolecular Fries rearrangement of the primary product phenyl benzoate, but indeed, the bimolecular reaction between phenyl benzoate and phenol mainly contributed to the formation of hydroxybenzophenones. The product distribution was greatly affected by the presence of Lewis-type acid sites in H-beta; it was suggested that the interaction between the aromatic ring and the electrophilic $\mathrm{Al}^{3+}$ species led to the preferred formation of $o$-hydroxybenzophenone, because of the decreased charge density on the $\mathrm{C}$ atom at the para position of the phenolic ring. H-Y zeolites were efficient than H-beta in phenyl benzoate transformation into hydroxybenzophenones.
\end{abstract}

Keywords: phenol; benzoic acid; hydroxybenzophenone; H-beta; benzoylation; acylation 


\section{Introduction}

The acylation of phenolic compounds is an important class of reactions with several applications in the chemical industry [1,2]. In fact, aromatic hydroxy ketones are intermediates for the synthesis of various pharmaceuticals and fragrances. $p$-Hydroxyacetophenone and $o$-hydroxyacetophenone are used for the synthesis of paracetamol and aspirin, respectively; the ortho isomer is also an intermediate for the synthesis of 4-hydroxycoumarin and flavanones. Furthermore, the acylation of resorcinol is an important process for the synthesis of a precursor for the UV-light absorbent for polymers, 4-o-octyl-o-hydroxybenzophenone [3].

In general, these reactions are catalyzed by homogeneous Friedel-Crafts Lewis-type catalysts; however, due to the environmental problems associated with the use of these compounds, alternative heterogeneous systems have been sought and, in some cases, successfully implemented in industrial uses. Furthermore, zeolites have been widely studied as catalysts for the acylation of both aromatic hydrocarbons and phenolics; several reports describe the reaction of these substrates, mainly in the liquid phase, but also in the gas phase, with different acylating agents, such as acyl halides (typically benzoyl chloride and acetyl chloride), anhydrides and even aliphatic and aromatic carboxylic acids, which are typically considered poorly reactive and, thus, react preferably with activated substrates [1,4-39].

A summary of acylations where the catalyst is made up of a zeolite is shown in Table 1. Amongst the various zeolites tested, H-beta typically offers a superior performance in terms of reactant conversion and selectivity to the desired product; this was suggested to be due to its pore structure. In some cases, however, H-Y also showed excellent performances.

Table 1. A summary of the literature data on acylation with zeolites.

\begin{tabular}{|c|c|c|c|c|}
\hline Substrate & Acylating Reagent & Desired Product & Catalyst & Ref. \\
\hline Cyclohexene & $\begin{array}{l}\text { Acetic anhydride, } \\
\text { acetyl chloride }\end{array}$ & Acetylcyclohexenes & H-Y, H-beta, H-mordenite & {$[33]$} \\
\hline Benzene & Benzoyl chloride & Benzophenone & $\mathrm{Ga}$, In-H-beta & {$[26]$} \\
\hline Toluene & Phthalic acid & 2-methylanthraquinone & H-Y, H-beta, H-mordenite & {$[39]$} \\
\hline Toluene & Benzoyl chloride & 4-methylbenzophenone & H-beta & {$[4]$} \\
\hline Toluene & Acetic anhydride & 4-methylacetophenone & H-beta (nano) & {$[8]$} \\
\hline$o$-Xylene & Benzoyl chloride & 3,4-dimethylbenzophenone & H-beta & {$[6]$} \\
\hline$m$-Xylene & $\begin{array}{l}\text { Benzoyl chloride, } \\
\text { benzoic anhydride }\end{array}$ & 2,4-dimethylbenzophenone & $\mathrm{H}-\mathrm{Y}$ & {$[40]$} \\
\hline Naphthalene & Benzoyl chloride & 2-benzoylnaphthalene & H-beta & {$[5]$} \\
\hline 2-Methoxynaphthalene & Acetic anhydride & 2-acetyl-6-methoxynaphthalene & H-beta, H-Y, ITQ-7 & {$[7,13,22,25,41]$} \\
\hline Biphenyl & Acetic anhydride & 4-acetylbiphenyl & H-Y, H-beta & {$[12]$} \\
\hline Biphenyl & Benzoyl chloride & 4-phenylbenzophenone & H-beta & {$[20]$} \\
\hline Chlorobenzene & 4-chlorobenozylchloride & 4,4'-dichlorobenzophenone & H-beta & {$[14]$} \\
\hline Phenol & Propionyl chloride & 4- and 2-hydroxypropiophenone & H-beta & {$[10]$} \\
\hline Phenol (gas-phase) & Acetic acid & $\begin{array}{c}\text { Phenyl acetate, } \\
\text { o-hydroxyacetophenone }\end{array}$ & H-Y, H-beta, H-ZSM-5 & {$[11,30,31]$} \\
\hline Phenol (gas-phase) & Acetic acid & $p$ - and $o$-hydroxyacetophenone & $\begin{array}{c}\text { Zn-exchanged } \mathrm{NaY} \text { or } \\
\text { ZSM-5 }\end{array}$ & {$[42]$} \\
\hline Phenol & Benzoic anhydride & $p$ - and $o$-hydroxybenzophenone & H-beta & [19] \\
\hline
\end{tabular}


Table 1. Cont.

\begin{tabular}{|c|c|c|c|c|}
\hline Substrate & Acylating Reagent & Desired Product & Catalyst & Ref \\
\hline Phenol & Acetic anhydride & $p$ - and $o$-hydroxyacetophenone & H-ZSM5 (Cu-, Co-doped) & {$[37]$} \\
\hline Phenol & Acetic acid & $p$ - and $o$-hydroxyacetophenone & HZSM-5, H-Y & {$[38,43]$} \\
\hline Phenol & Phenylacetate & $p$ - and $o$-hydroxyacetophenone & H-beta & {$[44]$} \\
\hline p-Cresol & $\begin{array}{l}\text { Acetic acid, propionic } \\
\text { acid, butyric acid, etc. }\end{array}$ & Various $o$-hydroxy ketones & H-beta & {$[45]$} \\
\hline Anisole & Octanoic acid & p-octanoyl anisole & H-beta & {$[24]$} \\
\hline Anisole & $\begin{array}{l}\text { Hexanoic, octanoic, } \\
\text { decanoic acids }\end{array}$ & 4-methoxyphenylalkylketone & H-beta, H-Y, H-mordenite & [29] \\
\hline Anisole & Acetic anhydride & $p$ - and $o$-methoxyacetophenone & H- beta, H-Y & {$[32,36]$} \\
\hline Guaiacol & Acetic anhydride & 2-methoxyphenyl acetate & H-Ferrierite & {$[16]$} \\
\hline Veratrole & $\begin{array}{c}\text { Benzoic anhydride, } \\
\text { benzoyl chloride }\end{array}$ & Dimethoxybenzophenone & H-Y, H-beta & {$[15]$} \\
\hline Veratrole & Propionyl chloride & 3,4-dimethoxypropiophenone & H-beta & {$[17]$} \\
\hline Dimethoxybenzenes & Various acyl chlorides & Various & $\mathrm{H}-\mathrm{Y}$ & {$[18]$} \\
\hline Veratrole & Acetic anhydride & 3-4-dimethoxyacetophenone & H-Y, H-beta & {$[9,21]$} \\
\hline Phenylacetate & Fries rearrangement & $p$ - and $o$-hydroxyacetophenone & H-beta & {$[23,27,46]$} \\
\hline Phenylacetate (gas-phase) & Fries rearrangement & $p$ - and $o$-hydroxyacetophenone & $\mathrm{H}_{3} \mathrm{PO}_{4} / \mathrm{ZSM}-5$ & {$[28]$} \\
\hline Phenylacetate & Fries rearrangement & $p$ - and $o$-hydroxyacetophenone & H-beta, H-Y, H-ZSM5 & {$[34]$} \\
\hline $\begin{array}{c}\text { Phenylacetate, phenyl } \\
\text { benzoate }\end{array}$ & Fries rearrangement & $p$ - and $o$-hydroxyacetophenone & H-ZSM5, H-ZSM12 & {$[35]$} \\
\hline
\end{tabular}

Other non-zeolitic, but heterogeneous catalysts have also been used, such as: (i) montmorillonites of the K series for the acetylation of various aliphatic and aromatic substrates $[47,48]$ and of aliphatic and aromatic alcohols [49], for the acylation of resorcinol with phenylacetic chloride [50] and after an exchange with various metals for the reaction between aromatic aldehydes and acetic anhydride to produce the corresponding 1,1-diacetates [51]; (ii) silica-supported phosphotungstic acid for the acylation of aromatic hydrocarbons with acrylic and crotonic acid [52,53], for the Fries rearrangement of phenyl benzoate [54] and for the acylation of anisole with acetic anhydride [55,56]; (iii) clay-supported Cs-phosphotungstic acid for the benzoylation of anisole with benzoyl chloride [57], for the benzoylation of $p$-xylene [58,59] and of phenol with benzoic acid (BA) to obtain $p$-hydroxybenzophenone (HBP) [60]; (iv) giant $\mathrm{P} / \mathrm{W}$ heteropolyacids for the acetylation of phenol with acetic anhydride [61] (the reactivity of heteropolyacids for Friedel-Crafts acylation was reviewed by Kozhevnikov [62]), and other P/W polyoxometalates for the acetylation of alcohols and phenols [61]; (v) NaGa-Mg hydrotalcite for the benzoylation of toluene with benzoyl chloride $[63,64]$; (vi) $\mathrm{EPZG}^{\circledR}$ for the acylation of 1-methoxynaphthalene and anisole with various acyl chlorides and anhydrides [65]; (vii) sulfated zirconia, even promoted with other metal oxides or supported over MCM-41, for the benzoylation of anisole with benzoic anhydride [66-70] or benzoyl chloride [71], for the acylation of phenol, anisole and chlorobenzene with acetic anhydride or benzoic anhydride [72-74], for the acylation of veratrole with acetic anhydride [75] and for the Fries rearrangement of 4-methylphenylbenzoate [76]; (viii) borate zirconia for the benzoylation of anisole with benzoyl chloride [77]; (ix) $\mathrm{Zr}$ hydroxide functionalized with trifluoromethanesulfonic acid for the benzoylation of biphenyl [78]; (x) Sn-doped sulfated zirconia for the benzoylation of anisole with benzoyl chloride [79]; (xi) triflic acid-functionalized Zr-TMS 
(zirconium oxide with a mesostructured framework; TMS, transition metal oxide mesoporous molecular sieves) for the benzoylation of biphenyl [80], of diphenyl ether to 4-phenoxybenzophenone [81] and of toluene to 4,4'-dimethylbenzophenone [82]; (xii) Fe-Zr phosphate for the benzoylation of different arenes [83]; (xiii) mesoporous UDCaT-5 (a sulphated tetragonal zirconia-based catalyst) for the acylation of anisole with propionic anhydride [84]; (xiv) KF/alumina for the benzoylation of phenolics with benzoyl chloride [85]; (xv) polystyrene-supported $\mathrm{GaCl}_{3}$ for the benzoylation of phenols with benzoic anhydride [86]; (xvi) $\mathrm{Fe}_{3} \mathrm{O}_{4}$ nanoparticles for the benzoylation of phenols with aryl aldehydes to obtain the substituted $o$-HBPs (xanthones) [87]; (xvii) $\mathrm{ZnO}$ for the $o$-benzoylation of alcohols (including phenol) with benzoyl chloride $[88,89]$ and $\mathrm{ZnAl}_{2} \mathrm{O}_{4} / \mathrm{SiO}_{2}$ composites for the acetylation of alcohols and phenols with acetic anhydride [90]; (xviii) mesoporous Al-KIT-6 (a cubic mesoporous silica with Al incorporated) for the gas-phase acylation of phenol to phenyl acetate with acetic acid [91]; (xix) Al-MCM-41 for the acylation of phenol with acetic acid in the gas-phase [31]; (xx) yttria-zirconia for the acylation of alcohols, thiols and amines with carboxylic acids [92]; (xxi) nafion-in-silica composite for the Fries rearrangement of phenyl acetate [34] and for anisole acylation with acetic anhydride (also with expanded $\mathrm{CO}_{2}$ as the solvent) [55]; (xxii) $\mathrm{WO}_{3} / \mathrm{ZrO}_{2}$ for the acylation of veratrole with acetic anhydride and of anisole with benzoic anhydride [93]; and (xxiii) $\mathrm{Ni} / \mathrm{SiO}_{2}$ for the acetylation of phenol, naphthol and other alcohols [94].

In regards to the synthesis of $p$ - and $o$-HBP (or other substituted benzophenones) or benzyl benzoates via $c$ - or $o$-benzoylation, respectively, papers in the literature describe the use of benzoyl chloride or benzyl trichloride also with various homogeneous catalysts: $\mathrm{AlCl}_{3}$ for phenol (and phenol derivatives containing 2,2,6,6,-tetramethylpiperidine) [95], $\mathrm{Cu}(\mathrm{OTf})_{2}$ and $\mathrm{Sn}(\mathrm{OTf})_{2}$ for anisole and veratrole [96,97], $\mathrm{Bi}(\mathrm{III})$ salts for phenol [98] and $\mathrm{Hf}(\mathrm{OTf})_{4}$ for phenol [99], even with carboxylic acids [100].

As shown in Table 1, there are no papers in the literature describing the use of zeolites for the benzoylation of phenol; there is only one paper reporting on phenol benzoylation with benzoic anhydride catalyzed by the H-beta zeolite [19] and one paper reporting about the benzoylation of phenol with BA using polyoxometalate catalyst [60]. In this latter case, Yadav et al. [60] reported that the first step of the reaction, catalyzed by $\mathrm{Cs}_{2.5} \mathrm{H}_{0.5} \mathrm{PW}_{12} \mathrm{O}_{40}$ supported over $\mathrm{K}-10$ clay, is the esterification, which is followed by Fries rearrangement towards hydroxybenzophenones (HBPs). The best selectivity to $p$-HBP was $32.5 \%$ at $70 \%$ BA conversion, with a phenol/BA ratio of $7 / 1$. In the paper of Chaube et al. [19], $\mathrm{H}$-beta turned out to be the more active zeolite for the production of HBPs. The selectivity to $p$-HBP was found to increase with the increase of the strength of acid sites; HBPs formed by both Fries rearrangement and acylation of phenol by phenyl benzoate.

Here, we report on a study aimed at finding zeolitic catalysts and conditions for the liquid-phase benzoylation of phenol with BA; the reaction was carried out in the absence of any solvent. Typically, the aim of this reaction is the production of HBPs, which are intermediates for dyes, pharmaceuticals and fragrances. In the current industrial production of HBPs, benzotrichlorides are produced first; they are then reacted with benzene in the presence of $\mathrm{AlCl}_{3}$, and afterwards, the adduct is hydrolysed into $p$-HBP. The direct reaction between phenol and $\mathrm{BA}$ is also carried out, using $\mathrm{BF}_{3}$ as a Lewis-type catalyst [19]. 


\section{Results and Discussion}

\subsection{Characterization of H-Beta Zeolites}

Table 2 summarizes the main characteristics of the four $\mathrm{H}$-beta zeolites used: the $\mathrm{Si} / \mathrm{Al}$ ratio (as stated by the supplier), the overall amount of ammonia desorbed (as determined by $\mathrm{NH}_{3}$-Thermal-Programmed -Desorption TPD), and main morphological features. As can be seen, the number of acid sites was not exactly in line with that expected based on the $\mathrm{Si} / \mathrm{Al}$ ratio; in fact, sample HB-75 had a smaller number of acid sites than HB-150, while the opposite would normally be expected. This seems to be attributable to an overestimation of the number of acid sites in HB-150.

Table 2. Main characteristics of the H-beta (HB) and H-Y (HY) zeolites used as catalysts for phenol benzoylation.

\begin{tabular}{|c|c|c|c|c|c|c|c|}
\hline Sample & $\begin{array}{c}\text { Si/Al, } \\
\text { Atomic } \\
\text { Ratio } \\
\end{array}$ & $\begin{array}{c}\text { Overall Amount } \\
\text { of } \mathrm{NH}_{3} \text { Desorbed } \\
\left.\text { (mmole } \mathrm{NH}_{3} / \mathrm{g}\right)\end{array}$ & $\begin{array}{c}\text { Micropore } \\
\text { Volume and Area } \\
\left(\mathrm{cm}^{3} / \mathbf{g}, \mathbf{~ m}^{2} / \mathrm{g}\right) \\
\end{array}$ & $\begin{array}{c}\text { Mesopore } \\
\text { Volume } \\
\left(\mathrm{cm}^{3} / \mathrm{g}\right) \\
\end{array}$ & $\begin{array}{c}\text { Total Pore } \\
\text { Volume } \\
\left(\mathrm{cm}^{3} / \mathrm{g}\right) \\
\end{array}$ & $\begin{array}{c}\text { Total Surface } \\
\text { Area } \\
\left(\mathrm{m}^{2} / \mathrm{g}\right) \\
\end{array}$ & $\begin{array}{l}\text { Crystallite Size } \\
\text { (nm; from XRD) }\end{array}$ \\
\hline HB-13 & 13 & 0.39 & $0.13,384$ & 0.55 & 0.70 & 575 & 18 \\
\hline HB-38 & 38 & 0.24 & $0.15,421$ & 0.94 & 1.10 & 636 & 16 \\
\hline HB-75 & 75 & 0.11 & $0.15,429$ & 0.99 & 1.16 & 645 & 16 \\
\hline HB-150 & 150 & 0.17 & $0.16,458$ & 0.17 & 0.38 & 641 & 27 \\
\hline HY-3 & 3 & $1.0 *$ & $\mathrm{Nd}$ & $\mathrm{Nd}$ & $\mathrm{Nd}$ & 584 & $\mathrm{Nd}$ \\
\hline HY-7 & 7.5 & $0.1 *$ & $\mathrm{Nd}$ & $\mathrm{Nd}$ & $\mathrm{Nd}$ & $550 *$ & $\mathrm{Nd}$ \\
\hline HY-100 & 100 & $<0.1 *$ & $\mathrm{Nd}$ & $\mathrm{Nd}$ & $\mathrm{Nd}$ & 814 & $\mathrm{Nd}$ \\
\hline
\end{tabular}

Nd: not determined; * as from the TOSOH website.

In regard to the strength of these sites, Figure 1 plots the relative concentration of the Lewis and Brønsted sites, as determined by means of FTIR spectra after pyridine adsorption, taking as reference bands those falling at 1455 and $1545 \mathrm{~cm}^{-1}$, respectively, and using the formula reported in the literature [101]. As can be seen, the sample with the greater Al content showed the higher fraction of strong Lewis sites, which is an expected result based on the fact that the latter is attributable to extra-framework Al species. The strength and relative amount of these Lewis sites decreased when the $\mathrm{Si} / \mathrm{Al}$ ratio was increased. Conversely, the zeolite with the stronger Brønsted sites was sample H-beta (HB)-150.

We also determined the degree of hydrophilicity of samples by means of $\mathrm{H}_{2} \mathrm{O}-\mathrm{TPD}$; Figure 2 shows that, as expected, the increased $\mathrm{Si} / \mathrm{Al}$ ratio led to samples with a lower affinity for water; however, the molar ratio between adsorbed $\mathrm{H}_{2} \mathrm{O}$ molecules and $\mathrm{Al}$ atoms increased, suggesting that a higher number of water molecules interacted with more isolated $\mathrm{Al}$ sites. 


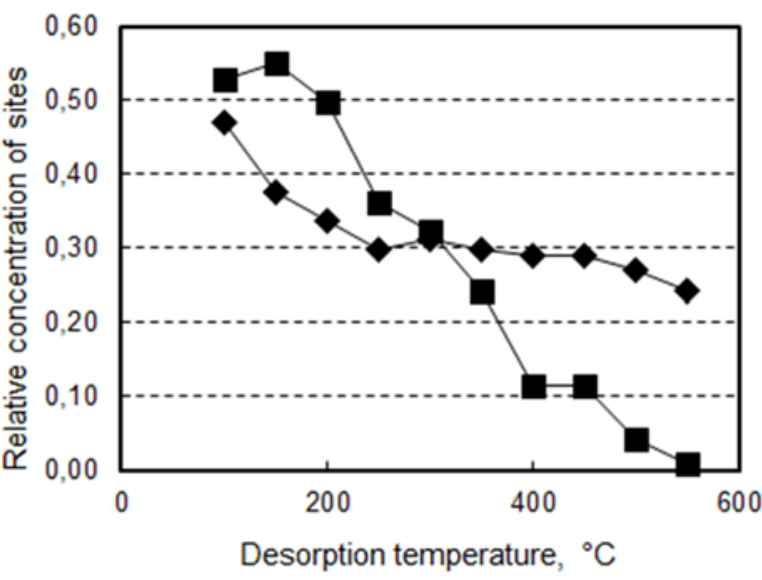

(A)

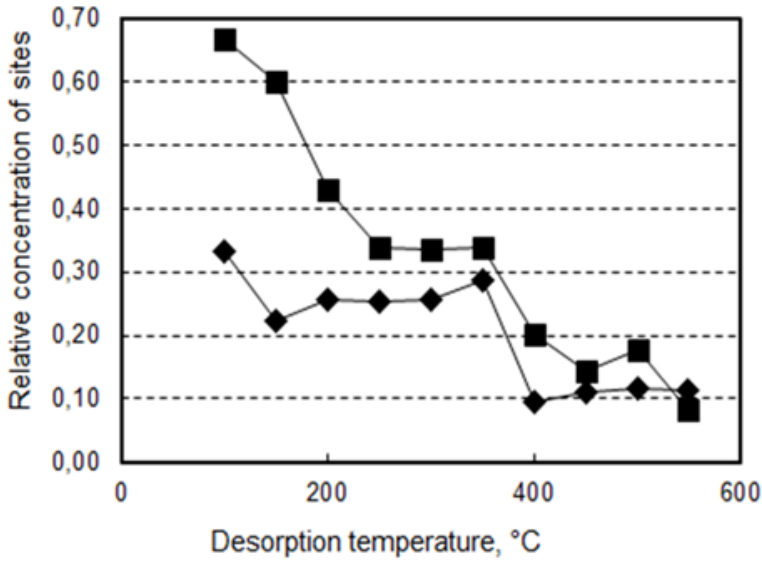

(C)

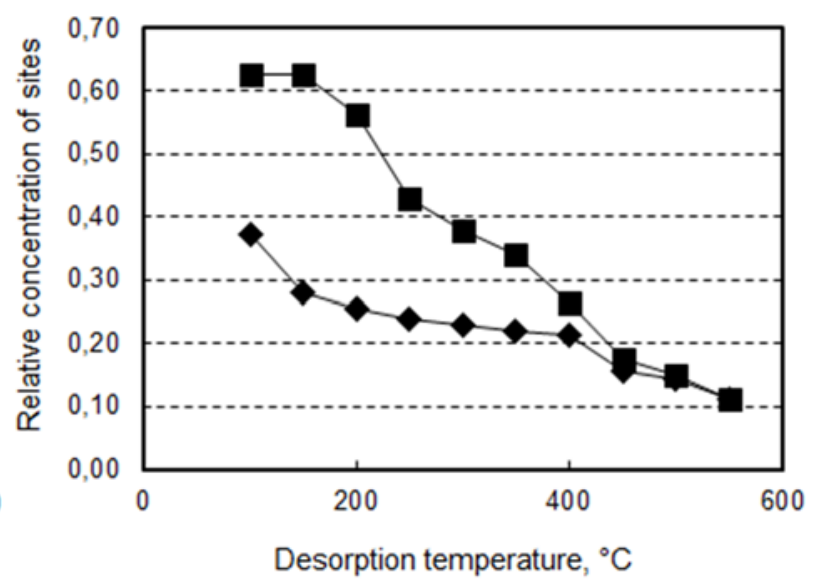

(B)

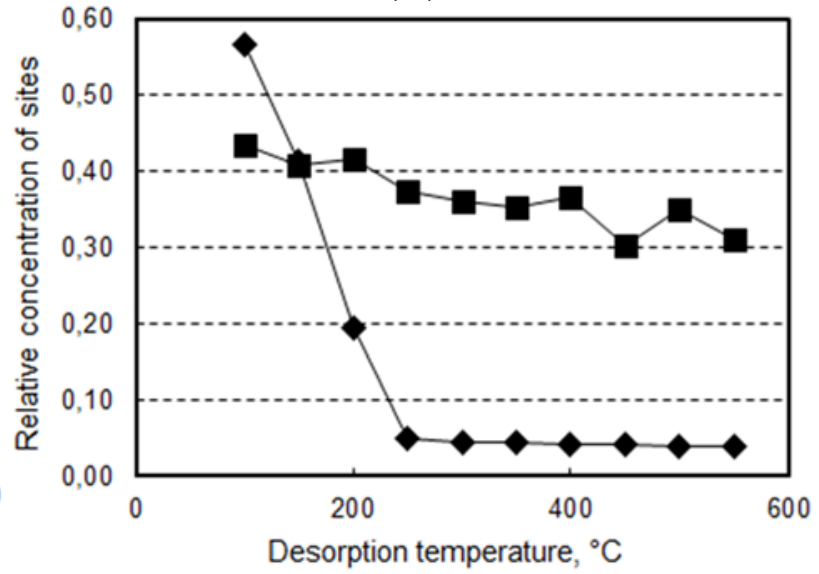

(D)

Figure 1. Relative concentration of Lewis ( $\bullet$ ) and Brønsted ( $\mathbf{})$ sites based on the pyridine desorption temperature, as determined by the intensity of the band associated with the pyridine adsorbed over the two types of sites. Samples: HB-13 (A), HB-38 (B), HB-75 (C) and HB-150 (D).

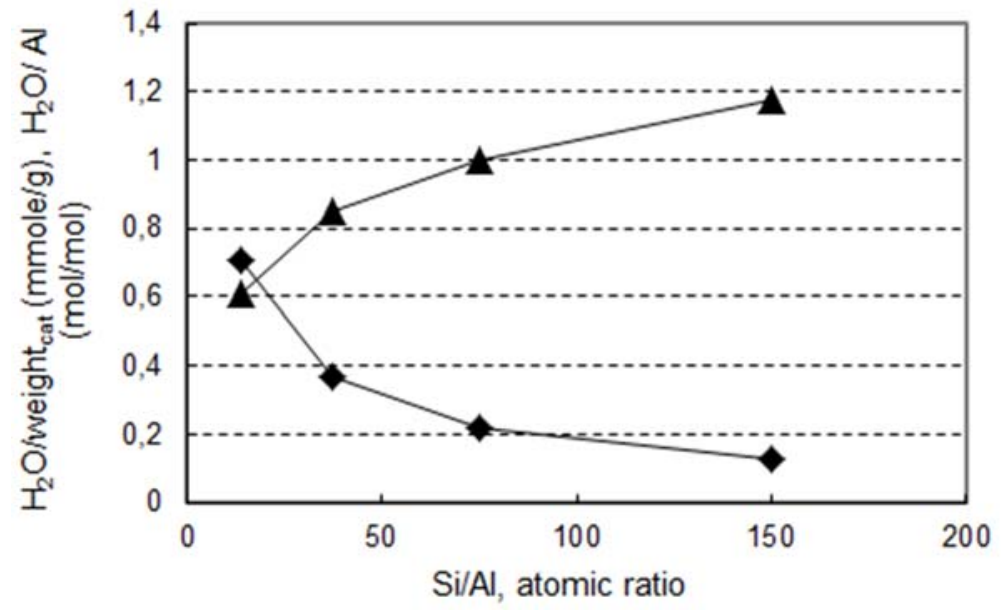

Figure 2. Ratio between amount of $\mathrm{H}_{2} \mathrm{O}$ adsorbed and catalyst weight $(\star)$ or the number of $\mathrm{Al}$ moles $(\boldsymbol{\Delta})$, based on the $\mathrm{Si} / \mathrm{Al}$ atomic ratio. Samples: H-beta zeolites. 


\subsection{Reactivity of H-Beta Zeolites}

Figure 3 plots phenol conversion based on reaction time and product selectivity based on phenol conversion for the four H-beta zeolites studied. There was no obvious relationship between the Al content in zeolites and the catalyst activity. Indeed, comparing phenol conversion at short reaction times, it was shown to increase when the Silica-to-Alumina Ratio SAR ratio decreased from 150 to 38, but then, a further increase in Al content (in sample HB-13) led to its decrease; thus, the most active sample was HB-38. This may mean that the activity was not only related to the number of active acid sites, but also to their strength. It is also important to note that, as reported in the literature, during the liquid-phase acylation of aromatics, the accumulation of heavy compounds may cause catalyst deactivation and a strong inhibition of reactant conversion [27,32,44]. Under our reaction conditions, however, the data shown in Figure 2 seem to rule out important deactivation phenomena; indeed, significant coking phenomena also could be ruled out, because spent catalysts did not appear as being covered by carbonaceous residua. However, HB-13 exhibited a slower rate of conversion increase during time; this might be due to a partial deactivation of Lewis sites (see below for the discussion on the role of acid sites); in fact, HB-13 was the sample showing the greater strength for Lewis acid sites.

Products were phenyl benzoate (PB), $o$ - and $p$-hydroxybenzophenone (HBP) and $O$ - and p-benzoylphenyl benzoate (BPB); the latter formed with selectivity no higher than $10 \%$ and were clearly more prominent with samples having the greatest SAR ratio; in fact, with HB-13, the formation of these compounds was negligible, despite the significant selectivity to HBP, which is a precursor for BPB formation.

With all catalysts, PB was clearly the only primary product, since its selectivity extrapolated at low conversion was $100 \%$. The formation of HBP occurred by consecutive transformations of the ester; it is also interesting to note that the molar ratio between the two HBP isomers (also shown in Figure 3) was very different depending on the sample characteristics. The formation of the para isomer was more facilitated with the catalyst that had the highest Al content (HB-150), with a $p$-/o-HBP selectivity ratio much greater than one, while it was less facilitated over the sample with the lowest $\mathrm{Al}$ content (HB-13), with a selectivity ratio much lower than one. Furthermore, in all samples, with the exception of HB-13, the para/ortho ratio increased with the increase in phenol conversion, up to a maximum value shown at 20\%-40\% phenol conversion, after which it decreased; lastly, all samples reached a $p$-/o-HBP selectivity ratio close to one.

These trends may have two different interpretations. The first is that two different mechanisms take place for PB transformation into HBPs:

(a) An intramolecular Fries rearrangement of PB, which does not involve phenol, and leads preferentially to the formation of $o-\mathrm{HBP}$. The greatest contribution of this reaction is registered with samples having the highest $\mathrm{Al}$ content, leading to a $p$-/o-HBP selectivity ratio lower than one with HB-13.

(b) An intermolecular reaction between PB and phenol, which leads to both of the two HBP isomers. The greatest contribution of this reaction is registered with samples having the lowest $\mathrm{Al}$ content, leading to a $p$-/o-HBP selectivity ratio greater than one with HB-150 and HB-75. 


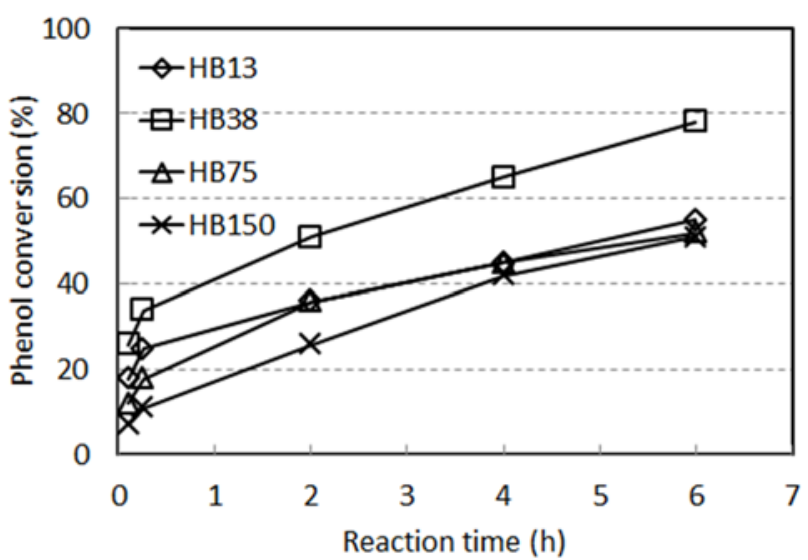

(A)

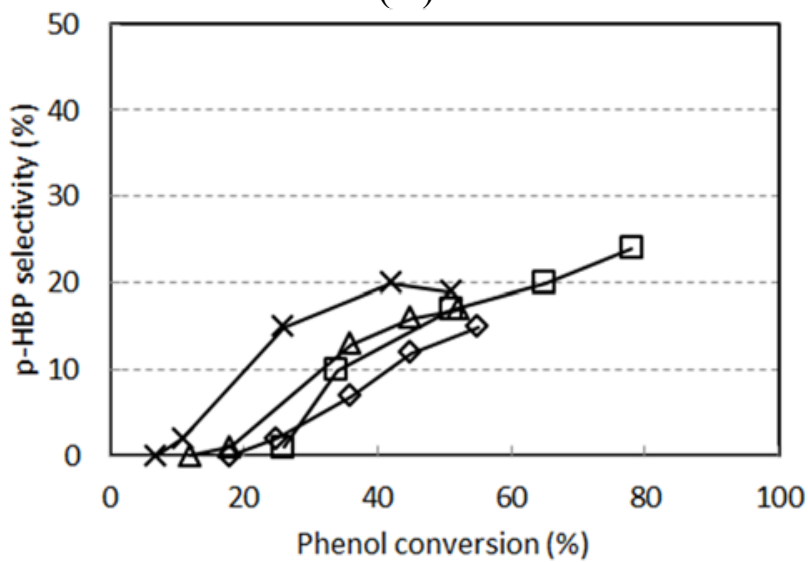

(C)

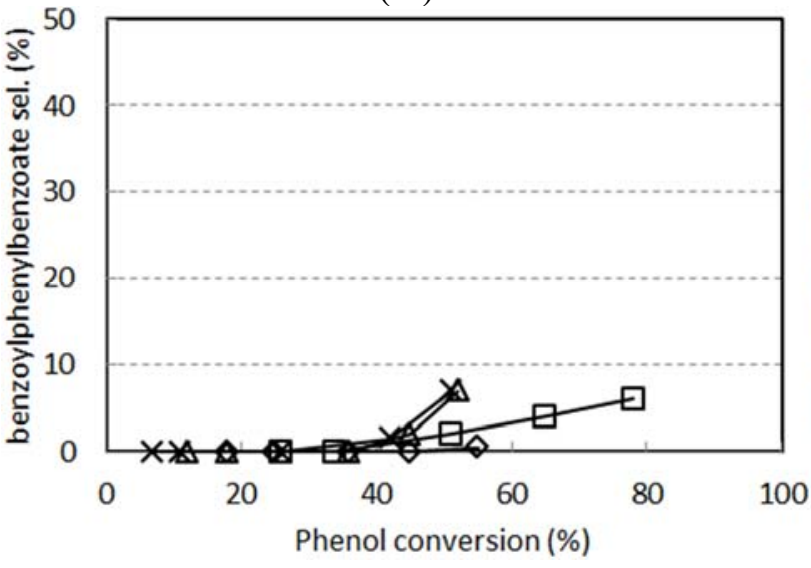

(E)

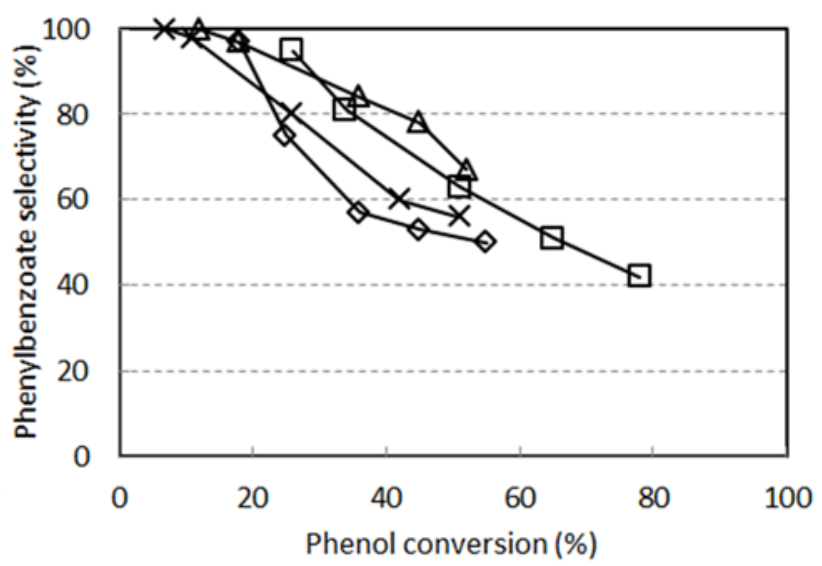

(B)

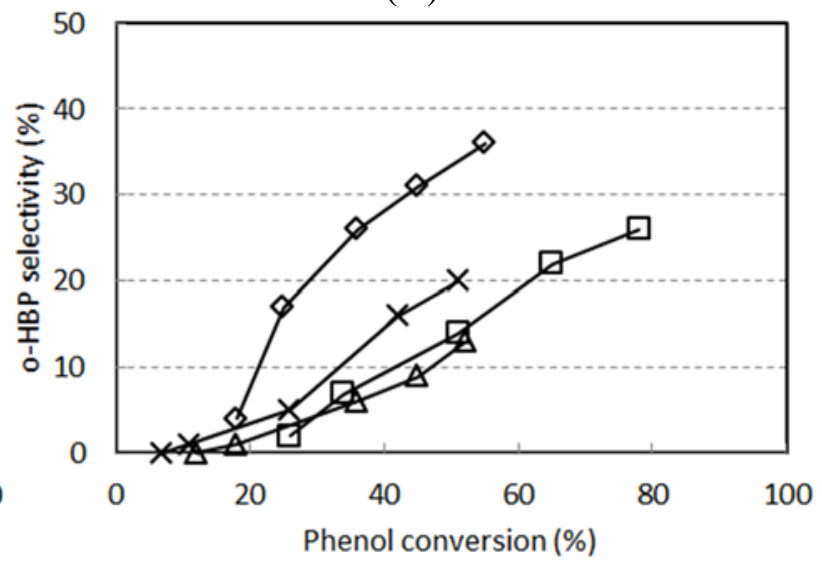

(D)

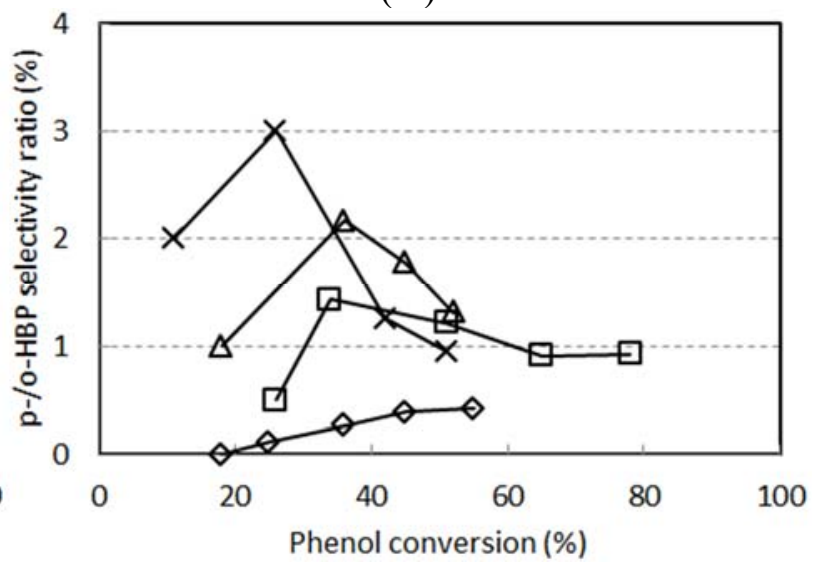

(F)

Figure 3. Phenol benzoylation with benzoic acid (BA): phenol conversion based on reaction time (A) and selectivity to phenylbenzoate (B), p-hydroxybenzophenone (C), $o$-hydroxybenzophenone (D) and benzoylphenylbenzoates $(\mathbf{E})$ based on phenol conversion at $\mathrm{T}=190{ }^{\circ} \mathrm{C}$. (F): selectivity ratio between $p$ - and $o$-hydroxybenzophenone. Catalysts: H-beta zeolites.

An important role in the reaction might be played by the different zeolite properties; with Al-rich zeolites, those showing a greater affinity for more polar molecules (Figure 2), it may be expected that the phenol/BA molar ratio inside pores is greater than with Al-poor zeolites. This might be the reason for the effects shown, i.e.,: (i) a maximum value for the $p$-/o-HBP selectivity ratio obtained at about 
$30 \%-40 \%$ phenol conversion; and (ii) a different trend in the selectivity ratio shown by samples, both effects being attributable to a different concentration of the two reactants inside pores and, thus, to a change in the relative contribution of intra- and inter-molecular reactions.

An alternative hypothesis is that the formation of HBPs occurs only by means of the bimolecular mechanism between PB and phenol. In this case, the different acidity of zeolites might be the reason for the different $p$-/o-HBP selectivity ratio shown. In particular, the stronger Lewis-type acidity shown by the H-beta with higher Al content might be responsible for an enhanced interaction with the phenol aromatic ring, which in turn might entail a lower delocalization of the negative charge over the ring itself; thus, the regio-selectivity of the reaction might be strongly affected by the decreased contribution of the mesomeric effect. Therefore, with catalysts showing the strongest Lewis-type acid sites, the ring-acylation at the ortho position might be more probable over the acylation at the para position, due to the prevailing contribution of the inductive effect, which exerts its effect on the ortho position only.

The trend observed for the $p$-/o-HBP selectivity ratio based on phenol conversion, with a maximum value registered at about $30 \%-40 \%$ conversion, may be due to the overlapping of two opposite effects. On the one hand, a progressive deactivation of the Lewis-acid sites, due to either the strong interaction of phenolics with the aromatic ring or the accumulation of water (the co-product in PB formation), causes the in situ transformation of the Lewis sites into Brønsted acid sites. On the other hand, under conditions of phenol scarcity (i.e., after 30\%-40\% phenol conversion), either the intramolecular rearrangement of PB into o-HBP might become kinetically preferred over the bimolecular reaction or an equilibration between the two isomers might lead the $p$-/o-HBP selectivity ratio to approach a value close to the equilibrium one.

In the literature, the role of Lewis sites in acylation reactions is also highlighted; it is reported that $\mathrm{P} / \mathrm{W}$ heteropoly salts or metal-exchanged clays are efficient catalysts for the acetylation of alcohols or of aromatic substrates, in which the reaction rate increases with the cation electronegativity. The reaction is initiated by the coordination of acetic anhydride to the metal cation, with polarization of the $\mathrm{C}-\mathrm{O}$ bond in the coordinated species [102]. In our case, instead, the main effect of the Lewis acidity is on the selectivity ratio between the two HBP isomers.

Additional experiments carried out with $\mathrm{PB}$ as the reactant will help clarify the aspects related to the reaction network and to the role of acid sites.

\subsection{Reactivity Experiments with $P B$}

Figure 4 plots the selectivity to products obtained by reacting PB over the HB-38 zeolite, based on phenol conversion. Unexpectedly, HBPs appeared to not be primary products of PB transformation, because their selectivity extrapolated at nil conversion was close to zero. This implies that the contribution of the intramolecular Fries rearrangement is negligible and that during phenol benzoylation, the formation of HBPs only occurs by means of the bimolecular reaction between PB and phenol. In the case of the reaction starting from $\mathrm{PB}$, the intermolecular reaction may only occur between two PB molecules, to produce mainly p-BPB (selectivity to the ortho isomer was very low) and phenol. A further consecutive reaction between phenol and BPB or phenol and PB leads to the production of HBP isomers, with the coproduction of PB or phenol, respectively (however, in the latter case, the decrease in phenol selectivity shown in Figure 4 would not be justified). A rather similar trend was observed during PB reaction with HB-150. 
The overall reaction network, as inferred from the experiments carried out starting from phenol and from PB, is shown in Scheme 1. Results suggest that differences shown among the H-beta samples are not due to the presence of various mechanisms for the transformation of phenyl benzoate into HBPs, but are instead attributable to the acidity features of the H-beta zeolites tested.

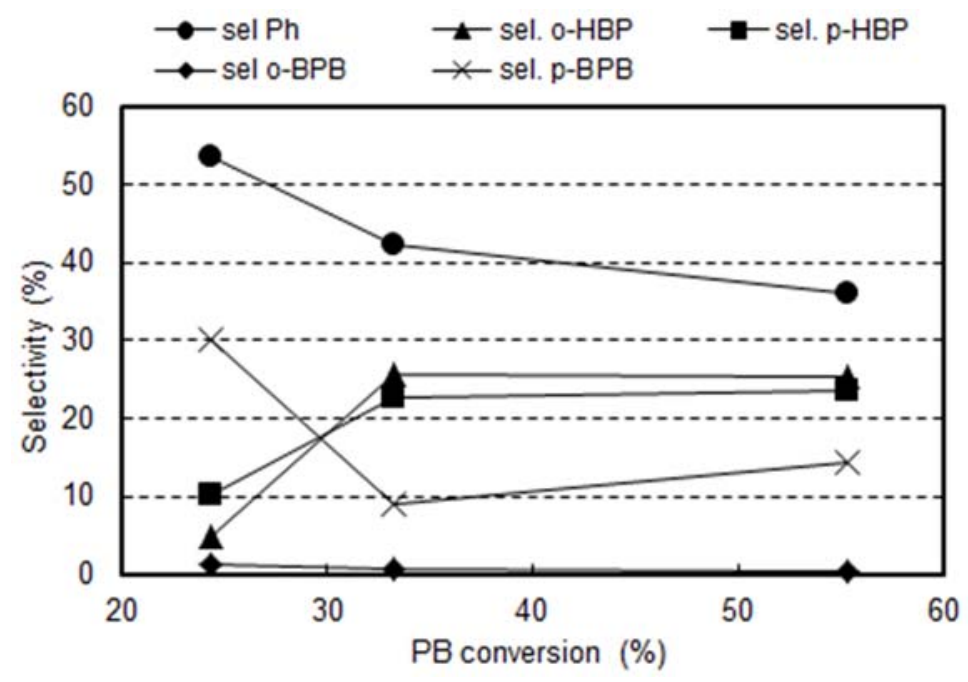

Figure 4. Phenyl benzoate $(\mathrm{PB})$ reactivity: selectivity to main products based on $\mathrm{PB}$ conversion. Temperature: $190{ }^{\circ} \mathrm{C}$.

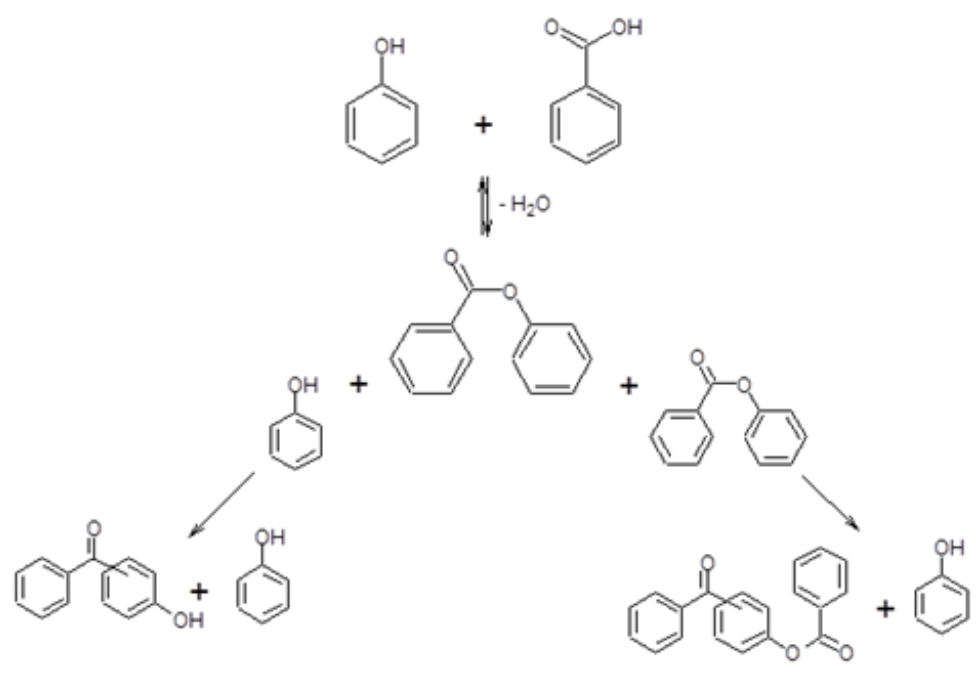

Scheme 1. Reaction scheme for phenol benzoylation with BA over H-beta zeolites.

\subsection{The Reactivity of $\mathrm{H}-\mathrm{Y}$ Zeolites}

We tested the reactivity of three different commercial H-Y zeolites (Table 2). In regard to the acidity of $\mathrm{H}-\mathrm{Y}$, it is reported in the literature that Lewis acidity may also play an important role, even for samples having low Al content (see, for instance [103], and the references therein).

The results of catalytic experiments are shown in Figure 5. As can be seen, in all cases, phenol conversion was lower than that obtained with H-beta zeolites. If the initial conversion is taken into account, e.g., at a $0.25 \mathrm{~h}$ reaction time, the scale of activity was HY-7 > HY-3 > HY-100; thus, in this 
case also, as with H-beta zeolites, the greatest activity was obtained with the intermediate SAR ratio. Overall, however, the activity was not much affected by the $\mathrm{Si} / \mathrm{Al}$ ratio.

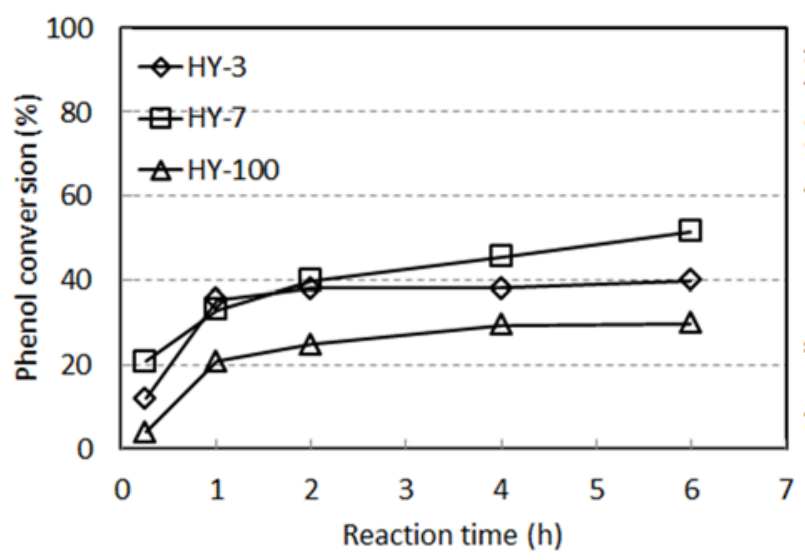

(A)

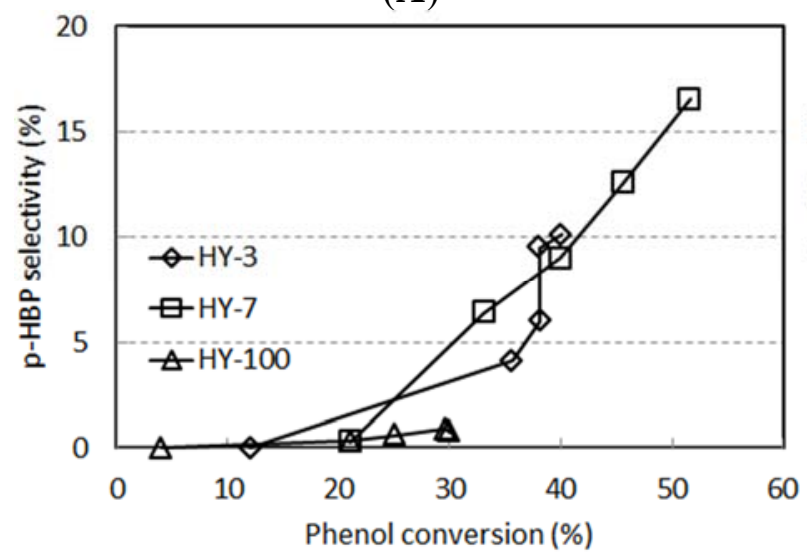

(C)

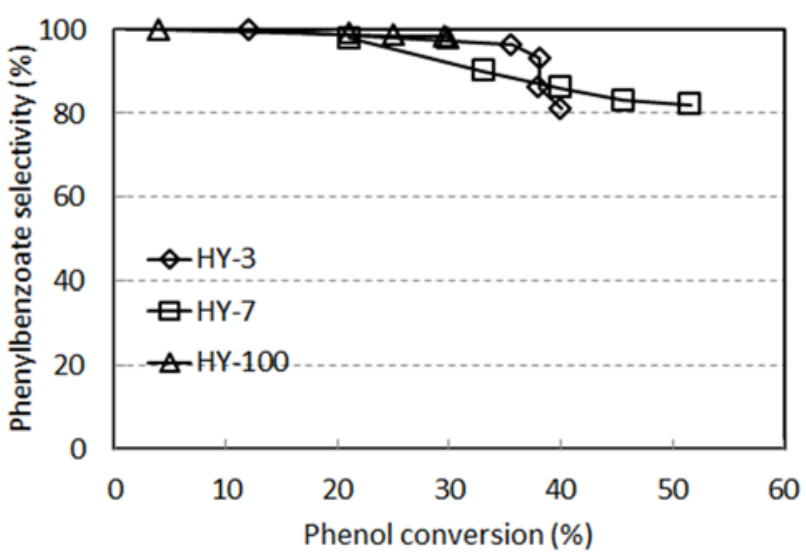

(B)

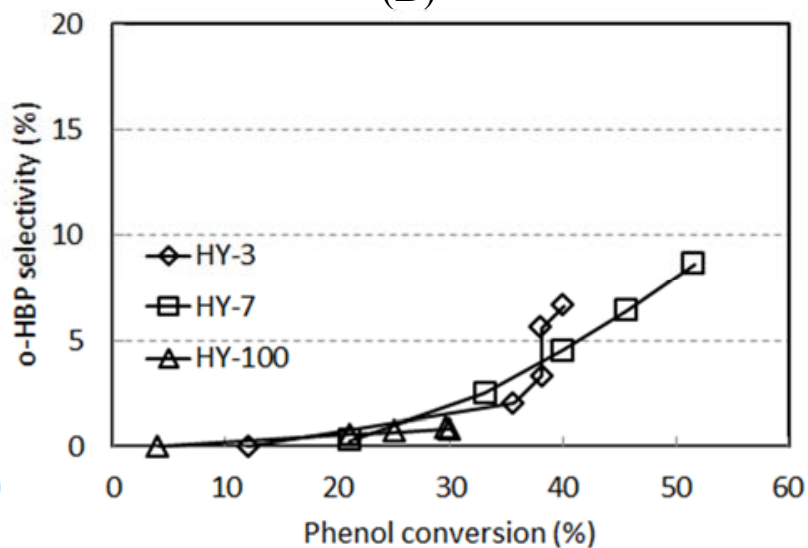

(D)

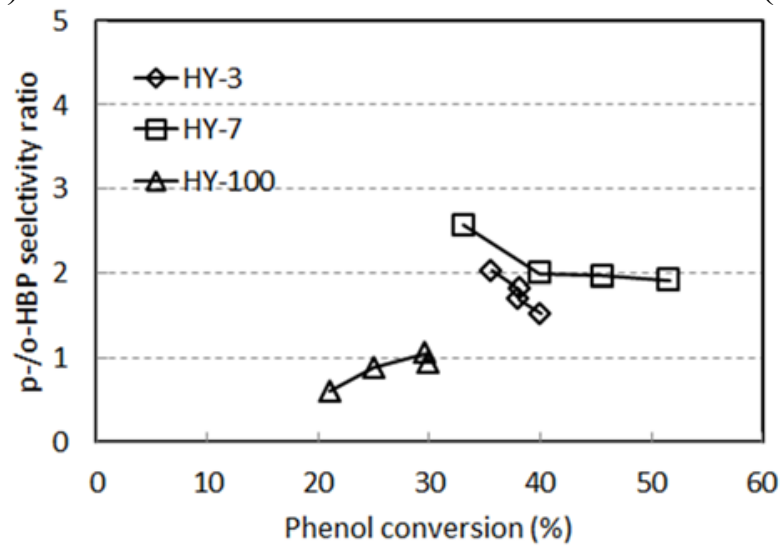

(E)

Figure 5. Phenol benzoylation with BA: phenol conversion based on reaction time (A) and selectivity to phenylbenzoate (B), to p-hydroxybenzophenone (C), and $o$-hydroxybenzophenone (D) based on phenol conversion at $T=190^{\circ} \mathrm{C}$. (E): selectivity ratio between $p$ - and $o$-hydroxybenzophenone. Catalysts: H-Y zeolites.

With these catalysts, also, PB was the only primary product, and the formation of HBPs occurred by the consecutive transformation of the ester. However, the selectivity to HBPs was lower than that shown with H-beta zeolites, even with the more active $\mathrm{H}-\mathrm{Y}$ sample. Therefore, $\mathrm{H}-\mathrm{Y}$ zeolites were also poorly efficient in the consecutive transformation of PB into HBPs; this is particularly apparent with the sample 
HY-100, which showed a negligible consecutive transformation of PB into HBP, even at $30 \%$ phenol conversion. With all of the H-Y zeolites tested, no BPB formation was shown.

The lowest $p$-/o-HBP selectivity ratio was achieved with HY-100, the highest with H-Y samples having the greater $\mathrm{Al}$ content, which is the opposite of what was observed with H-beta zeolites; however, in this case also, the selectivity ratio seemed to approach a value close to one when the phenol conversion was increased.

Even when we changed the BA/phenol molar ratio (Figure 6), the highest overall selectivity to HBPs achieved was not higher than $32 \%$. An excess of phenol, in experiments carried out at a BA/phenol molar ratio equal to 0.5 and 0.16 , should be kinetically unconducive to an intermolecular transformation of $\mathrm{PB}$ to HBPs compared to a Fries-type rearrangement; therefore, we might expect a change in the $p$-/o-HBP ratio in the presence of both the inter- and intra-molecular mechanisms of $\mathrm{PB}$ transformation into HBPs. With experiments carried out using a BA/phenol molar ratio $\leq 1$, the $p$-/o-HBP selectivity ratio was between 1.5 and 2.0, whereas in the case of the BA/phenol ratio of two, it was lower than 1.0.

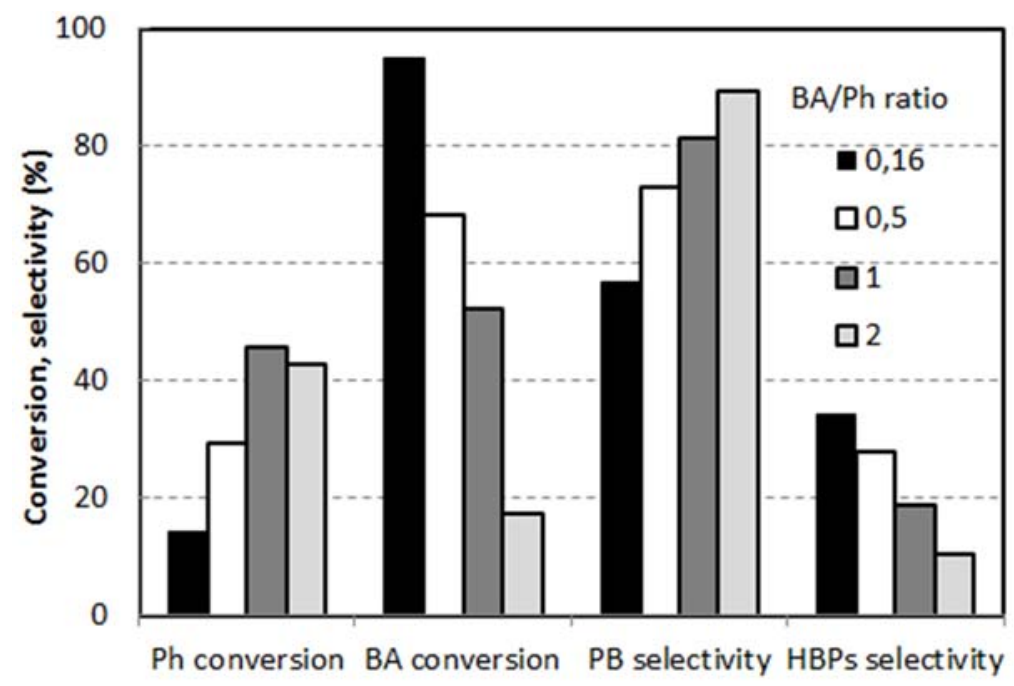

Figure 6. Effect of the $\mathrm{BA} / \mathrm{Ph}$ molar ratio on phenol $(\mathrm{Ph})$ and benzoic acid $(\mathrm{BA})$ conversion and selectivity to phenylbenzoate (PB) and hydroxybenzophenones (HBPs). Catalyst: HY-7, reaction time $4 \mathrm{~h}, \mathrm{~T}=190^{\circ} \mathrm{C}$.

In order to gain more information on the reaction network, we conducted some experiments in which we reacted PB; we observed that the peak conversion of PB was reached with HY-3 (43\%), the lowest with HY-100 (6\%) and the intermediate value of $18 \%$ for HY-7. These results were in line with the PB selectivity decrease registered in phenol benzoylation experiments, during which PB underwent almost no consecutive transformation with HY-100. Surprisingly, however, no HBP was formed in these experiments, with the exception of some traces observed with the most active HY-3 compound. The only products found were phenol and BA. On the one hand, this indicates the presence of water in the zeolites (the greater amount being obviously shown with the more hydrophilic zeolite), which are responsible for the hydrolysis of the ester, but on the other hand, this suggests that both the intramolecular Fries rearrangement and the intermolecular reaction between two molecules of PB are slowed greatly under these conditions with H-Y catalysts. 
It can be concluded that with $\mathrm{H}-\mathrm{Y}$ zeolites, the presence of water (which is generated in situ during phenol benzoylation tests) has a pronounced slowing effect on the rate of consecutive PB transformation into HPBs, thus explaining the lower selectivity to HBPs recorded with these catalysts. It is possible that Lewis acid sites, which play an important role in the reaction mechanism with H-beta, are strongly inhibited by the presence of water.

When we carried out the benzoylation of phenol with benzoic anhydride, a reaction that does not lead to the co-production of water, we obtained a greater phenol conversion, which is an expected result, because BA (the co-product in benzoylation with benzoic anhydride) is a more efficient leaving group than water (the co-product in benzoylation with BA). However, despite the greater phenol conversion achieved, the selectivity to HBPs still remained low (Figure 7); this indicates that the difference observed between H-beta and H-Y zeolites in phenol benzoylation with BA was not due to water and to its interaction with Lewis acid sites.

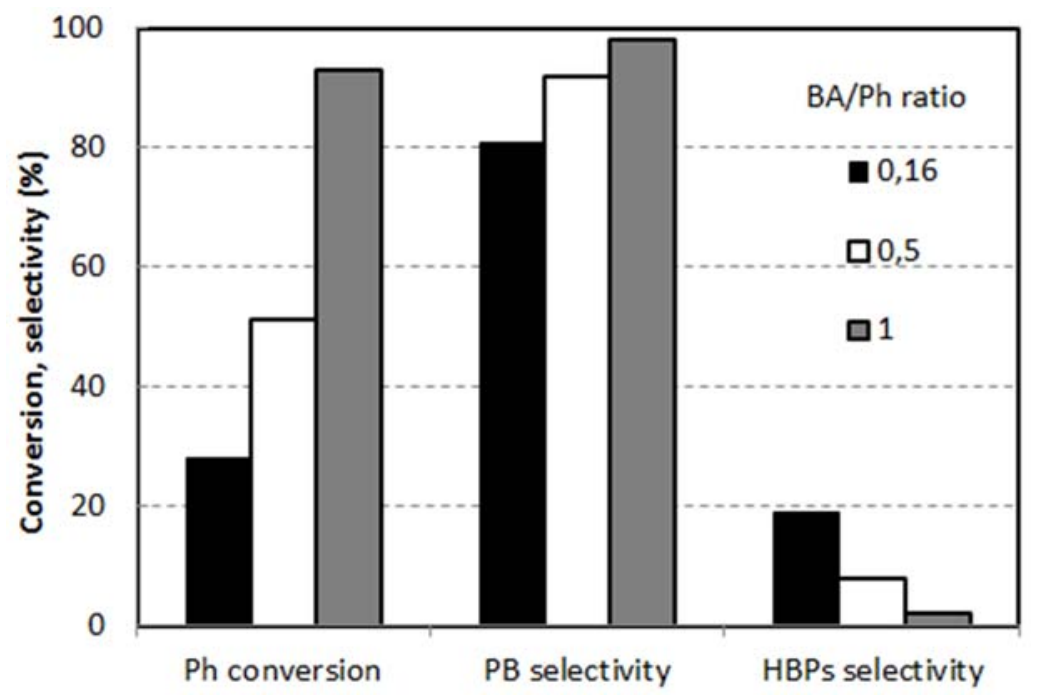

Figure 7. Effect of the benzoic anhydride/ $\mathrm{Ph}$ molar ratio on phenol $(\mathrm{Ph})$ conversion and selectivity to phenylbenzoate (PB) and hydroxybenzophenones (HBPs). Catalyst: HY-7, reaction time $4 \mathrm{~h}, \mathrm{~T}=190^{\circ} \mathrm{C}$.

Excellent performances in the benzoylation of phenol with benzoic anhydride were reported by Chaube et al. [19] with the use of an H-beta zeolite; the authors observed a $p$-/o-HBP selectivity ratio close to two, similar to that one also observed in our experiments with HY-7. However, a selectivity to HBPs as high as almost $70 \%$ at over $95 \%$ benzoic anhydride conversion could be obtained with the H-beta. Hoefnagel and Van Bekkum studied the acylation of resorcinol with benzoic acid, with H-beta in p-chlorotoluene solvent; a 70\% yield to 2,4-dihydroxybenzophenone was reported, with $20 \%$ residual resorcinol monobenzoate [104]. Indeed, the better performance of H-beta in acylation of phenolics is well known and widely described in the literature, for example in the acylation of anisole with acetic anhydride (a process developed by Rhodia); however, acylation of veratrole is preferably carried out with H-Y zeolites [2].

Overall, we can state that despite both the large number of papers reporting on the use of zeolites for the acylation of phenolics (see Table 1) and the various interpretations advanced to explain the superior performance of one zeolite type over others, a clear picture as to the possible reasons for the 
differences in the catalytic behavior for this reaction has not yet been produced. Furthermore, in our case, the better performance of H-beta zeolites over H-Y for HBPs' production, notwithstanding the well-known analogies of H-BEA and H-FAU zeolite types, is difficult to explain, even though it is clearly attributable to a remarkably less efficient transformation rate of the intermediately-formed $\mathrm{PB}$ with H-Y. This difference is greater between samples having the lowest Al content, i.e., HB-150 and HY-100; in fact, the latter catalyst was substantially inactive in PB conversion into HBPs. Further studies are needed in order to develop a better understanding of the main zeolite characteristics that affect the catalytic properties in phenolic acylation.

\section{Experimental Section}

H-beta zeolites: commercial samples purchased from Zeolyst International (Conshohocken, PA, USA) (HB-38, HB-75 and HB-150) and from ZEOCHEM (Uetikon am See, Switzerland) (HB-13) were used. H-Y zeolites: commercial samples were purchased from TOSOH (Tokyo, Japan) (HY-3, HY-7 and HY-100).

Porosimetry was determined using a Micromeritics (Norcross, GA, USA) ASAP 2020 instrument.

Thermal-programmed-desorption of ammonia (10\% in $\mathrm{He}$ ) was carried out using a TPDRO 1000 Thermo Finnigan Italia (Rodano, Italia) instrument. Samples were first pre-treated at $550{ }^{\circ} \mathrm{C}$ for $1 \mathrm{~h}$; then, pulses of ammonia were fed onto the sample maintained at a temperature of $180{ }^{\circ} \mathrm{C}$. The temperature was then raised $\left(10^{\circ} \mathrm{C} / \mathrm{min}\right)$ up to $550{ }^{\circ} \mathrm{C}$, and the sample was left at this temperature for $1 \mathrm{~h}$, until the complete desorption of the ammonia.

FTIR spectra in the transmission mode were recorded after the adsorption of pyridine vapors under a vacuum on a self-supported thin film of the sample. The sample was initially pre-treated at $550{ }^{\circ} \mathrm{C}$ for $2 \mathrm{~h}$; then, the cell was saturated with pyridine vapors at $100^{\circ} \mathrm{C}$, for $30 \mathrm{~min}$. Lastly, the sample was heated at increasing temperatures, and the IR spectrum was recorded at defined temperature intervals.

In a typical benzoylation reaction, phenol (Sigma-Aldrich, St. Louis, MO, USA) (0.1 g), benzoic acid (Sigma-Aldrich, St. Louis, MO, USA) (0.13 g) (molar ratio phenol/benzoic acid $=1)$ and the catalyst (10 wt. \% with respect to the reactants) were loaded without solvent in a sealed test tube equipped with a magnetic stirrer. The test tube was then placed in an oil bath and heated up to the temperature desired $\left(190-200{ }^{\circ} \mathrm{C}\right)$. After the reaction, the crude was cooled, diluted with HPLC acetone, filtered and analyzed. The reaction mixture was analyzed with a Thermo Focus from Thermo Fisher (Waltham, MA, USA) GC gas-chromatograph equipped with an FID detector and Agilent (Santa Clara, CA, USA) HP-5 column, using $n$-decane as the internal standard. The analysis conditions were: $60{ }^{\circ} \mathrm{C}$ for $0 \mathrm{~min}$, $40{ }^{\circ} \mathrm{C} / \mathrm{min}$ up to $280^{\circ} \mathrm{C}, 2 \mathrm{~min}$ at $280^{\circ} \mathrm{C}$.

\section{Conclusions}

Here, we report on the unprecedented reaction of phenol benzoylation with benzoic acid catalyzed by zeolites, which was carried out in the absence of solvent; this reaction is aimed at the production of hydroxybenzophenones, compounds of great interest for the chemical industry. H-beta zeolites offered a superior performance, in terms not only of activity, but also of selectivity to the desired compounds. The reaction network was found to consist of the primary reaction of phenol esterification with the formation of phenyl benzoate, which is then consecutively transformed into hydroxybenzophenones by 
means of an intermolecular reaction between the ester and phenol; conversely, the contribution of the Fries rearrangement seemed to be negligible. With H-beta zeolites, the Si/Al ratio significantly affected performance, especially in terms of the selectivity ratio between the two hydroxybenzophenone isomers. An important role was played by Lewis-type acid sites, which were most abundant with Al-richer zeolites. Conversely, in the case of $\mathrm{H}-\mathrm{Y}$ zeolites, the transformation of the ester into the desired ketones was greatly inhibited.

\section{Author Contributions}

G.G., S.P., F.B., P.M. and M.A. designed and performed experiments, and analyzed data. F.C. analyzed data and wrote the paper.

\section{Conflicts of Interest}

The authors declare no conflict of interest.

\section{References}

1. Sartori, G.; Maggi, R. Use of solid catalysts in Friedel-Crafts acylation reactions. Chem. Rev. 2006, 106, 1077-1104.

2. Bejblová, M.; Procházková, D.; Čejka, J. Acylation Reactions over Zeolites and Mesoporous Catalysts. ChemSusChem 2009, 2, 486-499.

3. Bolognini, M.; Cavani, F.; Cimini, M.; Pozzo, L.D.; Maselli, L.; Venerito, D.; Pizzoli, F.; Veronesi, G. An environmentally friendly synthesis of 2,4-dihydroxybenzophenone by the single-step o-mono-benzoylation of 1,3-dihydroxybenzene (resorcinol) and Fries rearrangement of intermediate resorcinol monobenzoate: the activity of acid-treated montmorillonite. Comptes Rendus Chim. 2004, 7, 143-150.

4. Singh, A.P.; Bhattacharya, D.; Sharma, S. Benzoylation of toluene with benzoyl chloride over zeolite catalysts. J. Mol. Catal. A 1995, 102, 139-145.

5. Bhattacharya, D.; Sharma, S.; Singh, A.P. Selective benzoylation of naphthalene to 2-benzoylnaphthalene using zeolite H-beta catalysts. Appl. Catal. A 1997, 150, 53-62.

6. Jacob, B.; Sugunan, S.; Singh, A.P. Selective benzoylation of $o$-xylene to 3,4-dimethylbenzophenone using various zeolite catalysts. J. Mol. Catal. A 1999, 139, 43-53.

7. Andy, P.; Garcia-Martinez, J.; Lee, G.; Gonzalez, H.; Jones, C. W.; Davis, M. E. Acylation of 2-Methoxynaphthalene and Isobutylbenzene over Zeolite Beta. J. Catal. 2000, 192, 215-223.

8. Botella, P.; Corma, A.; López-Nieto, J. M.; Valencia, S.; Jacquot, R. Acylation of Toluene with Acetic Anhydride over Beta Zeolites: Influence of Reaction Conditions and Physicochemical Properties of the Catalyst. J. Catal. 2000, 195, 161-168.

9. Moreau, P.; Finiels, A.; Meric, P. Acetylation of dimethoxybenzenes with acetic anhydride in the presence of acidic zeolites. J. Mol. Catal. A 2000, 154, 185-192.

10. Chaube, V.D.; Moreau, P.; Finiels, A.; Ramaswamy, A.V.; Singh, A.P. Propionylation of phenol to 4-hydroxypropiophenone over zeolite H-beta. J. Mol. Catal. A 2001, 174, 255-264. 
11. Neves, I.; Jayat, F.; Magnoux, P.; Perot, G.; Ribeiro, F.R.; Gubelmann, M.; Guisnet, M. Acylation of phenol with acetic acid over a HZSM-5 zeolite: the reaction scheme. J. Mol. Catal. 1994, 93, 169-179.

12. Escola, J.M.; Davis, M.E. Acylation of biphenyl with acetic anhydride and carboxylic acids over zeolite catalysts. Appl. Catal. A 2001, 214, 111-120.

13. Botella, P.; Corma, A.; Sastre, G. Al-ITQ-7, a Shape-Selective Zeolite for Acylation of 2-Methoxynaphthalene. J. Catal. 2001, 197, 81-90.

14. Venkatesan, C.; Jaimol, T.; Moreau, P.; Finiels, A.; Ramaswamy, A.V.; Singh, A.P. Liquid phase selective benzoylation of chlorobenzene. Catal. Lett. 2001, 75, 119-123.

15. Raja, T.; Singh, A.P.; Ramaswamy, A.V.; Finiels, A.; Moreau, P. Benzoylation of 1,2-dimethoxybenzene with benzoic anhydride and substituted benzoyl chlorides over large pore zeolites. Appl. Catal. A 2001, 211, 31-39.

16. Chavan, S.; Anand, R.; Pasupathy, K.; Rao, B. Catalytic acetylation of alcohols, phenols, thiols and amines with zeolite H-FER under solventless conditions. Green Chem. 2001, 320-322.

17. Jaimol, T.; Moreau, P.; Finiels, A.; Ramaswamy, A.V.; Singh, A.P. Selective propionylation of veratrole to 3,4-dimethoxypropiophenone using zeolite H-beta catalysts. Appl. Catal. A 2001, 214, $1-10$.

18. Bigi, F.; Carloni, S.; Flego, C.; Maggi, R.; Mazzacani, A.; Rastelli, M.; Sartori, G. HY zeolite-promoted electrophilic acylation of methoxyarenes with linear acid chlorides. J. Mol. Catal. A 2002, 178, 139-146.

19. Chaube, V.D.; Moreau, P.; Finiels, A.; Ramaswamy, A.V.; Singh, A.P. A novel single step selective synthesis of 4-hydroxybenzophenone (4-HBP ) using zeolite H-beta. Catal. Lett. 2002, 79, 89-94.

20. Chidambaram, M.; Venkatesan, C.; Moreau, P.; Finiels, A.; Ramaswamy, A.V.; Singh, A.P. Selective benzoylation of biphenyl to 4-phenylbenzophenone over zeolite H-beta. Appl. Catal. A 2002, 224, 129-140.

21. Guignard, C.; Pédron, V.; Richard, F.; Jacquot, R.; Spagnol, M.; Coustard, J.M.; Pérot, G. Acylation of veratrole by acetic anhydride over H $\beta$ and HY zeolites: Possible role of di- and triketone by-products in the deactivation process. Appl. Catal. A 2002, 234, 79-90.

22. Meric, P.; Finiels, A.; Moreau, P. Kinetics of 2-methoxynaphthalene acetylation with acetic anhydride over dealuminated HY zeolites. J. Mol. Catal. A 2002, 189, 251-262.

23. Wang, H.; Zou, Y. Modified beta zeolite as catalyst for Fries rearrangement reaction. Catal. Lett. 2003, 86, 163-167.

24. Beers, A.E.W.; Van Bokhoven, J.A.; De Lathouder, K.M.; Kapteijn, F.; Moulijn, J.A. Optimization of zeolite Beta by steaming and acid leaching for the acylation of anisole with octanoic acid: A structure-activity relation. J. Catal. 2003, 218, 239-248.

25. Botella, P.; Corma, A.; Navarro, M. T.; Rey, F.; Sastre, G. On the shape selective acylation of 2-methoxynaphthalene over polymorph C of Beta (ITQ-17). J. Catal. 2003, 217, 406-416.

26. Choudhary, V. R.; Jana, S. K.; Patil, N. S.; Bhargava, S. K. Friedel-Crafts type benzylation and benzoylation of aromatic compounds over HY zeolite modified by oxides or chlorides of gallium and indium. Microporous Mesoporous Mater. 2003, 57, 21-35. 
27. Heitling, E.; Roessner, F.; Van Steen, E. Origin of catalyst deactivation in Fries rearrangement of phenyl acetate over zeolite H-Beta. J. Mol. Catal. A 2004, 216, 61-65.

28. Ghiaci, M.; Abbaspur, A.; Kalbasi, R.J. Internal versus external surface active sites in ZSM-5 zeolite: Part 1. Fries rearrangement catalyzed by modified and unmodified $\mathrm{H}_{3} \mathrm{PO}_{4} / \mathrm{ZSM}-5$. Appl. Catal. A 2006, 298, 32-39.

29. Wagholikar, S.G.; Niphadkar, P.S.; Mayadevi, S.; Sivasanker, S. Acylation of anisole with long-chain carboxylic acids over wide pore zeolites. Appl. Catal. A 2007, 317, 250-257.

30. Padró, C.L.; Sad, M.E.; Apesteguía, C.R. Acid site requirements for the synthesis of o-hydroxyacetophenone by acylation of phenol with acetic acid. Catal. Today 2006, 116, 184-190.

31. Padró, C.L.; Apesteguía, C.R. Acylation of phenol on solid acids: Study of the deactivation mechanism. Catal. Today 2005, 107-108, 258-265.

32. Freese, U.; Heinrich, F.; Roessner, F. Acylation of aromatic compounds on H-Beta zeolites. Catal. Today 1999, 49, 237-244.

33. Armengol, E.; Corma, A.; Fernández, L.; García, H.; Primo, J. Acid zeolites as catalysts in organic reactions. Acetylation of cyclohexene and 1-methylcyclohexene. Appl. Catal. A 1997, 158, $323-335$.

34. Heidekum, A.; Harmer, M.A.; Hoelderich, W.F. Highly Selective Fries Rearrangement over Zeolites and Nafion in Silica Composite Catalysts: A Comparison. J. Catal. 1998, 176, 260-263.

35. Vogt, A.; Kouwenhoven, H. W.; Prins, R. Fries rearrangement over zeolitic catalysts. Appl. Catal. A 1995, 123, 37-49.

36. Wei, H.; Liu, K.; Xie, S.; Xin, W.; Li, X.; Liu, S.; Xu, L. Determination of different acid sites in Beta zeolite for anisole acylation with acetic anhydride. J. Catal. 2013, 307, 103-110.

37. Subba Rao, Y.V.; Kulkarni, S.J.; Subrahmanyam, M.; Rama Rao, A.V. An improved acylation of phenol over modified ZSM-5 catalysts. Appl. Catal. A 1995, 133, L1-L6.

38. Padró, C.L.; Apesteguía, C.R. Gas-phase synthesis of hydroxyacetophenones by acylation of phenol with acetic acid. J. Catal. 2004, 226, 308-320.

39. Hou, Q.; Zheng, B.; Bi, C.; Luan, J.; Zhao, Z.; Guo, H.; Wang, G.; Li, Z. Liquid-phase cascade acylation/dehydration over various zeolite catalysts to synthesize 2-methylanthraquinone through an efficient one-pot strategy. J. Catal. 2009, 268, 376-383.

40. Fang, R.; Harvey, G.; Kouwenhoven, H.W.; Prins, R. Effects of non-framework alumina in the acylation of xylene over USY. Appl. Catal. A 1995, 130, 67-77.

41. Patil, S.P.; Yadav, G.D. Selective acylation of 2 methoxynaphthalene by large pore zeolites: Catalyst selection through molecular modeling. Comput. Biol. Chem. 2003, 27, 393-404.

42. Padró, C.L.; Rey, E.A.; González Peña, L.F.; Apesteguía, C.R. Activity, selectivity and stability of Zn-exchanged $\mathrm{NaY}$ and ZSM5 zeolites for the synthesis of $o$-hydroxyacetophenone by phenol acylation. Microporous Mesoporous Mater. 2011, 143, 236-242.

43. Guisnet, M.; Lukyanov, D.B.; Jayat, F.; Magnoux, P.; Hap, H. Kinetic modeling of phenol acylation with acetic acid on HZSM5. Ind. Eng. Chem. Res. 1995, 34, 1624-1629.

44. Rohan, D.; Canaff, C.; Magnoux, P.; Guisnet, M. Origin of the deactivation of HBEA zeolites during the acylation of phenol with phenylacetate. J. Mol. Catal. A 1998, 129, 69-78.

45. Chandra Shekara, B.M.; Jai Prakash, B.S.; Bhat, Y.S. Microwave-induced deactivation-free catalytic activity of BEA zeolite in acylation reactions. J. Catal. 2012, 290, 101-107. 
46. Jayat, F.; Picot, M.J.S.; Guisnet, M. Solvent effects in liquid phase Fries rearrangement of phenyl acetate over a HBEA zeolite. Catal. Lett. 1996, 41, 181-187.

47. Li, A.-X.; Li, T.-S.; Ding, T.-H. Montmorillonite K-10 and KSF as remarkable acetylation catalysts. Chem. Commun. 1997, 1389-1390.

48. Li, T.; Li, A. Acylation of alcohols, phenols, thiols and amines. J. Chem. Soc. Perkin Trans. 1 1998, 1913-1917.

49. Choudary, B.M.; Bhaskar, V.; Lakshmi Kantam, M.; Koteswara Rao, K.; Raghavan, K.V. Acylation of alcohols with carboxylic acids; the evolution of compatible acidic sites in montmorillonites. Green Chem. 2000, 2, 67-70.

50. Békássy, S.; Farkas, J.; Agai, B.; Figueras, F. Selectivity of $C$-versus $O$-acylation of diphenols by clay catalysts. I. Acylation of resorcinol with phenylacetyl chloride. Top. Catal. 2000, 13, 287-290.

51. Jankovič, L.; Komadel, P. Metal cation-exchanged montmorillonite catalyzed protection of aromatic aldehydes with $\mathrm{Ac}_{2} \mathrm{O}$. J. Catal. 2003, 218, 227-233.

52. De Castro, C.; Primo, J.; Corma, A. Heteropolyacids and large-pore zeolites as catalysts in acylation reactions using $\alpha, \beta$-unsaturated organic acids as acylating agents. J. Mol. Catal. A 1998, 134, 215-222.

53. Castro, C.; Corma, A.; Primo, J. On the acylation reactions of anisole using $\alpha, \beta$-unsaturated organic acids as acylating agents and solid acids as catalysts: A mechanistic overview. J. Mol. Catal. A 2002, 177, 273-280.

54. Kozhevnikova, E.F.; Rafiee, E.; Kozhevnikov, I.V. Fries rearrangement of aryl esters catalysed by heteropoly acid: Catalyst regeneration and reuse. Appl. Catal. A 2004, 260, 25-34.

55. Sarsani, V.S.R.; Lyon, C.J.; Hutchenson, K.W.; Harmer, M.A.; Subramaniam, B. Continuous acylation of anisole by acetic anhydride in mesoporous solid acid catalysts: Reaction media effects on catalyst deactivation. J. Catal. 2007, 245, 184-190.

56. Bachiller-Baeza, B.; Anderson, J.A. FTIR and reaction studies of the acylation of anisole with acetic anhydride over supported HPA catalysts. J. Catal. 2004, 228, 225-233.

57. Yadav, G.D.; Asthana, N.S.; Kamble, V.S. Cesium-substituted dodecatungstophosphoric acid on K-10 clay for benzoylation of anisole with benzoyl chloride. J. Catal. 2003, 217, 88-99.

58. Yadav, G.D.; Asthana, N.S.; Kamble, V.S. Friedel-crafts benzoylation of p-xylene over clay supported catalysts: Novelty of cesium substituted dodecatungstophosphoric acid on K-10 clay. Appl. Catal. A 2003, 240, 53-69.

59. Yadav, G.D.; Asthana, N.S.; Salgaonkar, S.S. Regio-selective benzoylation of xylenes over caesium modified heteropolyacid supported on K-10 clay. Clean Technol. Environ. Policy 2004, 6, 105-113.

60. Yadav, G.D.; George, G. Single step synthesis of 4-hydroxybenzophenone via esterification and Fries rearrangement: Novelty of cesium substituted heteropoly acid supported on clay. J. Mol. Catal. A 2008, 292, 54-61.

61. Heravi, M.M.; Behbahani, F.K.; Bamoharram, F.F. $\mathrm{H}_{14}\left[\mathrm{NaP}_{5} \mathrm{~W}_{30} \mathrm{O}_{110}\right]$ : A heteropoly acid catalyzed acetylation of alcohols and phenols in acetic anhydride. J. Mol. Catal. A 2006, 253, 16-19.

62. Kozhevnikov, I.V. Friedel-Crafts acylation and related reactions catalysed by heteropoly acids. Appl. Catal. A 2003, 256, 3-18. 
63. Choudhary, V.R.; Jana, S.K.; Mandale, A.B. Highly active, reusable and moisture insensitive catalyst obtained from basic Ga-Mg-hydrotalcite anionic clay for Friedel-Crafts type benzylation and acylation reactions. Catal. Lett. 2001, 74, 95-98.

64. Choudhary, V.R.; Jana, S.K.; Narkhede, V.S. Benzylation and benzoylation of substituted benzenes over solid catalysts containing Ga- and Mg-oxides and/or chlorides derived from Ga-Mg-hydrotalcite by its $\mathrm{HCl}$ pre-treatment or calcination. Appl. Catal. A 2002, 235, 207-215.

65. Veverkova, E.; Meciarova, M.; Gotov, B.; Toma, S. Microwave assisted acylation of methoxyarenes catalyzed by EPZG catalyst. Green Chem. 2002, 4, 361-365.

66. Trunschke, A.; Deutsch, J.; Müller, D.; Lieske, H.; Quaschning, V.; Kemnitz, E. Nature of surface deposits on sulfated zirconia used as catalyst in the benzoylation of anisole. Catal. Lett. 2002, 83, 271-279.

67. Zane, F.; Melada, S.; Signoretto, M.; Pinna, F. Active and recyclable sulphated zirconia catalysts for the acylation of aromatic compounds. Appl. Catal. A 2006, 299, 137-144.

68. Signoretto, M.; Breda, A.; Somma, F.; Pinna, F.; Cruciani, G. Mesoporous sulphated zirconia by liquid-crystal templating method. Microporous Mesoporous Mater. 2006, 91, 23-32.

69. Ghedini, E.; Signoretto, M.; Pinna, F.; Cerrato, G.; Morterra, C. Gas and liquid phase reactions on MCM-41/SZ catalysts. Appl. Catal. B 2006, 67, 24-33.

70. Ghedini, E.; Signoretto, M.; Pinna, F.; Cruciani, G. Mesoporous silica-zirconia systems for catalytic applications. Catal. Lett. 2008, 125, 359-370.

71. Melada, S.; Signoretto, M.; Somma, F.; Pinna, F.; Cerrato, G.; Meligrana, G.; Morterra, C. Gas-and liquid-phase reactions on sulphated zirconia prepared by precipitation. Catal. Lett. 2004, 94, 193-198.

72. Deutsch, J.; Trunschke, A.; Mu, D. Different acylating agents in the synthesis of aromatic ketones on sulfated zirconia. Catal. Lett. 2003, 88, 9-15.

73. Signoretto, M.; Torchiaro, A.; Breda, A.; Pinna, F.; Cerrato, G.; Morterra, C. Study on reuse of metal oxide-promoted sulphated zirconia in acylation reactions. Appl. Catal. B 2008, 84, 363-371.

74. Ratnam, K.J.; Reddy, R.S.; Sekhar, N.S.; Kantam, M.L.; Figueras, F. Sulphated zirconia catalyzed acylation of phenols, alcohols and amines under solvent free conditions. J. Mol. Catal. A 2007, 276, 230-234.

75. Breda, A.; Signoretto, M.; Ghedini, E.; Pinna, F.; Cruciani, G. Acylation of veratrole over promoted SZ/MCM-41 catalysts: Influence of metal promotion. Appl. Catal. A 2006, 308, 216-222.

76. Clark, J. H.; Dekamin, M. G.; Moghaddam, F. M. Genuinely catalytic Fries rearrangement using sulfated zirconia. Green Chem. 2002, 4, 366-368.

77. Patil, P.T.; Malshe, K.M.; Kumar, P.; Dongare, M.K.; Kemnitz, E. Benzoylation of anisole over borate zirconia solid acid catalyst. Catal. Commun. 2002, 3, 411-416.

78. Chidambaram, M.; Venkatesan, C.; Rajamohanan, P.R.; Singh, A.P. Synthesis of acid functionalized mesoporous $\mathrm{Zr}-\mathrm{O}-\mathrm{SO}_{2}-\mathrm{CF}_{3}$ catalysts; heterogenization of $\mathrm{CF}_{3} \mathrm{SO}_{3} \mathrm{H}$ over mesoporous $\mathrm{Zr}(\mathrm{OH}) 4$. Appl. Catal. A 2003, 244, 27-37.

79. Sakthivel, R.; Prescott, H.A.; Deutsch, J.; Lieske, H.; Kemnitz, E. Synthesis, characterization, and catalytic activity of $\mathrm{SO}_{4} / \mathrm{Zr}_{1-x} \mathrm{Sn}_{x} \mathrm{O}_{2}$. Appl. Catal. A 2003, 253, 237-247. 
80. Chidambaram, M.; Curulla-Ferre, D.; Singh, A.P.; Anderson, B.G. Synthesis and characterization of triflic acid-functionalized mesoporous Zr-TMS catalysts: Heterogenization of $\mathrm{CF}_{3} \mathrm{SO}_{3} \mathrm{H}$ over Zr-TMS and its catalytic activity. J. Catal. 2003, 220, 442-456.

81. Parambadath, S.; Chidambaram, M.; Singh, A.P. Synthesis, characterization and catalytic properties of benzyl sulphonic acid functionalized Zr-TMS catalysts. Catal. Today 2004, 97, 233-240.

82. Landge, S.M.; Chidambaram, M.; Singh, A.P. Benzoylation of toluene with p-toluoyl chloride over triflic acid functionalized mesoporous Zr-TMS catalyst. J. Mol. Catal. A 2004, 213, 257-266.

83. Gawande, M.B.; Deshpande, S.S.; Sonavane, S.U.; Jayaram, R.V. A novel sol-gel synthesized catalyst for Friedel-Crafts benzoylation reaction under solvent-free conditions. J. Mol. Catal. A 2005, 241, 151-155.

84. Yadav, G.D.; George, G. Friedel-Crafts acylation of anisole with propionic anhydride over mesoporous superacid catalyst UDCaT-5. Microporous Mesoporous Mater. 2006, 96, 36-43.

85. Jain, S.K.; Meena, S.; Singh, V.P.; Bharate, J.B.; Joshi, P.; Singh, V.P.; Vishwakarma, R.A.; Bharate, S.B. KF/alumina catalyzed regioselective benzylation and benzoylation using solventfree grind-stone chemistry. RSC Adv. 2012, 2, 8929-8933.

86. Rahmatpour, A. Polystyrene-supported $\mathrm{GaCl}_{3}$ : A new, highly efficient and recyclable heterogeneous Lewis acid catalyst for acetylation and benzoylation of alcohols and phenols. Comptes Rendus Chim. 2012, 15, 1048-1054.

87. Ramani, T.; Umadevi, P.; Prasanth, K.L.; Sreedhar, B. Synthesis of ortho-Hydroxybenzophenones Catalyzed by Magnetically Retrievable $\mathrm{Fe}_{3} \mathrm{O}_{4}$ Nanoparticles under Ligand-Free Conditions. European J. Org. Chem. 2013, 6021-6026.

88. Tamaddon, F.; Amrollahi, M.A.; Sharafat, L. A green protocol for chemoselective $O$-acylation in the presence of zinc oxide as a heterogeneous, reusable and eco-friendly catalyst. Tetrahedron Lett. 2005, 46, 7841-7844.

89. Moghaddam, F.M.; Saeidian, H. Controlled microwave-assisted synthesis of $\mathrm{ZnO}$ nanopowder and its catalytic activity for O-acylation of alcohol and phenol. Mater. Sci. Eng. B. 2007, 139, 265-269.

90. Farhadi, S.; Jahanara, K. $\mathrm{ZnAl}_{2} \mathrm{O}_{4} @ \mathrm{SiO}_{2}$ nanocomposite catalyst for the acetylation of alcohols, phenols and amines with acetic anhydride under solvent-free conditions. Chin. J. Catal. 2014, 35, 368-375.

91. Prabhu, A.; Kumaresan, L.; Palanichamy, M.; Murugesan, V. Synthesis and characterization of aluminium incorporated mesoporous KIT-6: Efficient catalyst for acylation of phenol. Appl. Catal. A 2009, 360, 59-65.

92. Kumar, P.; Pandey, R.K.; Bodas, M.S.; Dagade, S.P.; Dongare, M.K.; Ramaswamy, A.V. Acylation of alcohols, thiols and amines with carboxylic acids catalyzed by yttria-zirconia-based Lewis acid. J. Mol. Catal. A 2002, 181, 207-213.

93. Signoretto, M.; Ghedini, E.; Menegazzo, F.; Cerrato, G.; Crocellà, V.; Bianchi, C.L. Aerogel and xerogel WO3/ZrO2 samples for fine chemicals production. Microporous Mesoporous Mater. 2013, 165, 134-141.

94. Alam, M.; Rahman, A.; Alandis, N.M.; Shaik, M.R. Ni/Silica catalyzed acetylation of phenols and naphthols: An eco-friendly approach. Arab. J. Chem. 2014, 7, 53-56. 
95. Zakrzewski, J.; Szymanowski, J. 2-Hydroxybenzophenone UV-absorbers containing 2,2,6,6-tetramethylpiperidine (HALS) group-benzoylation of corresponding phenol derivatives. Polym. Degrad. Stab. 2000, 67, 279-283.

96. Singh, R.P.; Kamble, R.M.; Chandra, K.L.; Saravanan, P.; Singh, V.K. An efficient method for aromatic Friedel-Crafts alkylation, acylation, benzoylation, and sulfonylation reactions. Tetrahedron 2001, 57, 241-247.

97. Saravanan, P.; Singh, V.K. An efficient method for acylation reactions. Tetrahedron Lett. 1999, 40, 2611-2614.

98. Mohammadpoor-baltork, I.; Aliyan, H.; Khosropour, A.R. Bismuth (III) salts as convenient and efficient catalysts for the selective acetylation and benzoylation of alcohols and phenols. Tetrahedron 2001, 57, 5851-5854.

99. Kobayashi, S.; Moriwaki, M.; Hachiya, I. Hafnium trifluoromethanesulfonate $\left(\mathrm{Hf}(\mathrm{OTf})_{4}\right)$ as an efficient catalyst in the Fries rearrangement and direct acylation of phenol and naphthol derivatives. Tetrahedron Lett. 1996, 37, 2053-2056.

100. Kobayashi, S.; Moriwaki, M.; Hachiya, I. Catalytic direct $C$-acylation of phenol and naphthol derivatives using carboxylic acids as acylating reagents. Tetrahedron Lett. 1996, 37, 4183-4186.

101. Emeis, C.A. Determination of Integrated Molar Extinction Coefficients for Infrared Absorption Bands of Pyridine Adsorbed on Solid Acid Catalysts. J. Catal. 1993, 141, 347-354.

102. Shimizu, K.; Satsuma, A. Toward a rational control of solid acid catalysis for green synthesis and biomass conversion. Energy Environ. Sci. 2011, 4, 3140-3153.

103. Phung, T.K.; Busca, G. On the Lewis acidity of protonic zeolites. Appl. Catal. A 2015, 504, 151-157.

104. Hoefnagel, A.J.; Van Bekkum, H. Direct Fries reaction of resorcinol with benzoic acids catalyzed by zeolite H-beta. Appl. Catal. A 1993, 97, 87-102.

(C) 2015 by the authors; licensee MDPI, Basel, Switzerland. This article is an open access article distributed under the terms and conditions of the Creative Commons Attribution license (http://creativecommons.org/licenses/by/4.0/). 